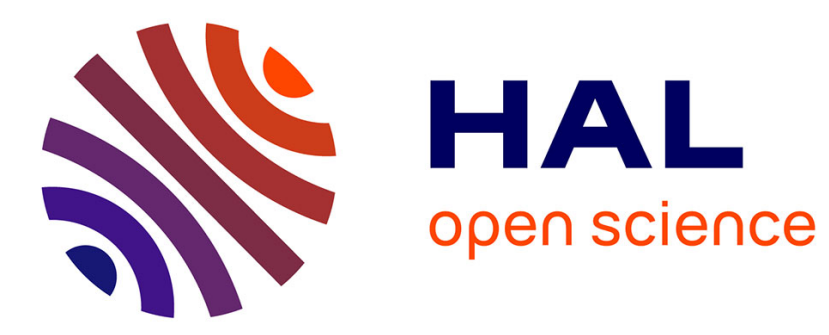

\title{
Optical Alignment of Si-Containing Nanodomains Formed by Photoresponsive Amorphous Block Copolymer Thin Films
}

Mitica Cezar Spiridon, Nils Demazy, Cyril Brochon, Eric Cloutet, Georges Hadziioannou, Karim Aissou, Guillaume Fleury

\section{To cite this version:}

Mitica Cezar Spiridon, Nils Demazy, Cyril Brochon, Eric Cloutet, Georges Hadziioannou, et al.. Optical Alignment of Si-Containing Nanodomains Formed by Photoresponsive Amorphous Block Copolymer Thin Films. Macromolecules, 2020, 10.1021/acs.macromol.9b01551 . hal-02429692

\section{HAL Id: hal-02429692 https://hal.science/hal-02429692}

Submitted on 6 Jan 2020

HAL is a multi-disciplinary open access archive for the deposit and dissemination of scientific research documents, whether they are published or not. The documents may come from teaching and research institutions in France or abroad, or from public or private research centers.
L'archive ouverte pluridisciplinaire HAL, est destinée au dépôt et à la diffusion de documents scientifiques de niveau recherche, publiés ou non, émanant des établissements d'enseignement et de recherche français ou étrangers, des laboratoires publics ou privés. 


\title{
Optical Alignment of Si-Containing Nanodomains Formed by Photo- Responsive Amorphous Block Copolymer Thin Films
}

\author{
Mitica Cezar Spiridon, ${ }^{1 \#}$ Nils Demazy, ${ }^{1 \#}$ Cyril Brochon, ${ }^{1}$ Eric Cloutet, ${ }^{1}$ Georges Hadziioannou, ${ }^{1}$ \\ Karim Aissou, ${ }^{1 \dagger^{*}}$ Guillaume Fleury ${ }^{1 *}$ \\ ${ }^{1}$ Univ. Bordeaux, CNRS, Bordeaux INP, LCPO, UMR 5629, F-33600, Pessac, France \\ ${ }^{\dagger}$ Current address: Institut Européen des Membranes, Université de Montpellier - CNRS - ENSCM, \\ 300 Avenue du Professeur Emile Jeanbrau, F-34090 Montpellier, France \\ "Both authors contributed equally to the manuscript \\ E-mail: karim.aissou@umontpellier.fr,gfleury@enscbp.fr
}

\begin{abstract}
A series of amorphous block copolymers (BCPs), consisting of a low glass transition polydimethylsiloxane (PDMS) block associated with a photo-responsive azobenzene-containing poly(disperse red 1 methacrylate-co-alkyl methacrylate) (P(DR1MA-co-RMA)) block, was prepared from a PDMS macro-chain transfer agent used for the reversible addition-fragmentation chain-transfer (RAFT) copolymerization of binary mixtures of methacrylate monomers of various compositions. The resulting BCPs containing up to $40 \mathrm{wt}$ \% of azo-dye exhibit low dispersity attesting a good control of the RAFT polymerization through the copolymerization of the DR1MA and RMA units. Long-range ordered in-plane PDMS cylinders were produced by exposing the (ascast) disordered BCP thin films to a p-polarized laser beam, in order to orthogonally align the azogroups with the polarization direction, prior to promote the microphase-separation of the BCP domains with a solvent vapor annealing (SVA) treatment. Conversely, the photo-induced
\end{abstract}


alignment of the azo-chromophores is not effective within microphase-separated BCP thin films since randomly oriented PDMS features are observed after exposure to a $p$-polarized laser light.

Keywords: block copolymer, self-assembly, azobenzene, surface relief grating, photo-induced alignment 


\section{Introduction.}

Block copolymers (BCPs) bearing azobenzene (azo) moieties constitute an attractive class of advanced materials since multifunctional surfaces comprising laterally-ordered nanoscale features on a periodic surface corrugation pattern, called surface relief grating (SRG), can be created due to an efficient photo-alignment and mass transfer of the BCP chains, triggered by the azobenzene cis-trans isomerization. ${ }^{1-4}$ For instance, pioneer works by Ikeda and Seki groups have demonstrated that the optical alignment of cylinder-forming liquid-crystalline (LC) BCP thin films was achievable by using a linearly polarized light to directionally orient the azo-mesogens. ${ }^{5,6}$ SRG formed as a result of the mass transport induced by the photoisomerization of azo-moieties is another interesting property of microphase-separated LC BCP thin films that was also explored by Seki and coll. ${ }^{7,8}$ In these studies, a thickness dependent orientation of the cylindrical nanodomains incorporated into the micrometer scale corrugated relief was demonstrated since the in-plane and out-of-plane orientations of the BCP features were precisely observed on the thin and thick regions of the SRG, respectively.

Besides, the directed self-assembly (DSA) of laterally-ordered BCP patterns over large scale have been achieved from thickness-gradient BCP films induced by dewetting ${ }^{9}$ as well as from microphase-separated BCP thin films deposited onto sinusoidally shaped SRG formed by amorphous azo-containing polymer layers, ${ }^{10,11}$ wrinkled graphene layers surfaces ${ }^{12-14}$ or faceted surfaces. ${ }^{15,16}$ In particular, the relative stability of the BCP nanostructure deposited onto sinusoidally shaped SRG was recently investigated in the framework of the self-consistent field theory (SCFT) in order to better apprehend the combined effect of substrate corrugation and its surface energy. ${ }^{17}$ Conversely, the perfect photo-alignment of microphase-separated BCP features formed by amorphous azo-based BCP thin films has never been demonstrated. In this regard, we 
designed a series of amorphous poly(dimethylsiloxane)-block-poly(disperse red 1 methacrylateco-alkyl methacrylate) (PDMS-b-P(DR1MA-co-RMA)) BCPs as photoactive materials in order to explore the combinations of different treatment processes on the formation of long range ordered in-plane PDMS cylinders oriented along an arbitrary direction.

The synthesis of the PDMS-based BCPs seldom follows a straightforward pathway. ${ }^{18}$ Usually, a telechelic PDMS is firstly designed by anionic polymerization followed by a modification of the chain end-group for its further use as macro-initiator or macro-chain transfer agent in controlled radical polymerization. ${ }^{19-23}$ Such multistep approaches allow access to welldefined functional PDMS-based BCPs. On the other hand, disperse red 1 (DR1)-containing polymers are usually synthesized by a polymer analogous reaction route rather than by the azomonomer polymerization. ${ }^{24,25}$ Indeed, the success of the direct polymerization of the azomonomers strongly depends on the reactivity of the azo-dye with the growing chain active centers, challenging its control as the dye loading increases. As a result, the polymerization of the DR1 monomers is often hindered by the inherent low reactivity caused by the bulkiness and the inhibition effect of this particular functional groups. ${ }^{26,27}$ Therefore, a group tolerant polymerization method has to be considered in combination with the use of suitable co-monomers for an improved polymerization control. RAFT polymerization has been successfully used in the synthesis of azo$\mathrm{BCPs}$, i.e. amphiphilic, liquid crystalline and stimuli responsive polymers. ${ }^{28-31}$ Most of the azoBCPs obtained by RAFT were designed with "reactive” azo-monomers, i.e. monomers with a long and flexible spacer between the azo-moiety and the polymerizable fragment and without strong activating and/or deactivating groups substituted on the aromatic ring (electronic "push-pull" system as in DR1). However, such design is rather destined for liquid crystalline azo-BCPs ${ }^{4}$ than for SRGs forming materials, i.e. amorphous DR1 containing polymers which are known as the 
gold standard for SRG applications. ${ }^{32,33}$ Only few reports describe the RAFT polymerization of azo-monomers containing short spacers and a pseudo-stilbene type azo-moiety, as this monomer design decreases its reactivity towards polymerization. ${ }^{34,35}$ To the best of our knowledge, DR1MA RAFT copolymerization with two different methacrylate derivatives was solely reported by Hoogenboom and coll. and the corresponding azo-polymers designed for sensing application embedded only 3-5 wt. \% DR1MA. ${ }^{31,35}$ Hence up to date there is no information available on azopolymers embedding higher amounts of DR1MA via RAFT (co)polymerization which are required for an effective SRG formation (i.e., dye content higher than ca. $30 \mathrm{wt} . \%$ ) to eventually produce laterally-ordered BCP features.

In this work, a series of amorphous PDMS-b-P(DR1MA-co-RMA) BCPs containing up to 40 wt. \% azo-dye was prepared via a well-controlled RAFT polymerization. By using an original method, combining the SRG photoinscription into the PDMS-b-P(DR1MA-co-RMA) layers and the microphase-separation of the BCP features by SVA, laterally-ordered in-plane PDMS cylinders over large area were demonstrated broadening the toolset inherent to the manipulation of the self-assembly of BCP features. Indeed, such long-range ordered Si-containing cylinders aligned along an arbitrary direction can eventually be oxidized under oxygen plasma to produce line and space patterns for directed self-assembly lithography. ${ }^{36-38}$

\section{Results and discussion.}

Synthesis of amorphous azo-containing block copolymers. Herein, a straightforward approach employing a combination of the anionic and RAFT polymerizations has been successfully used 
for the synthesis of various well-defined amorphous DR1-containing BCPs, as presented in

\section{Scheme 1.}

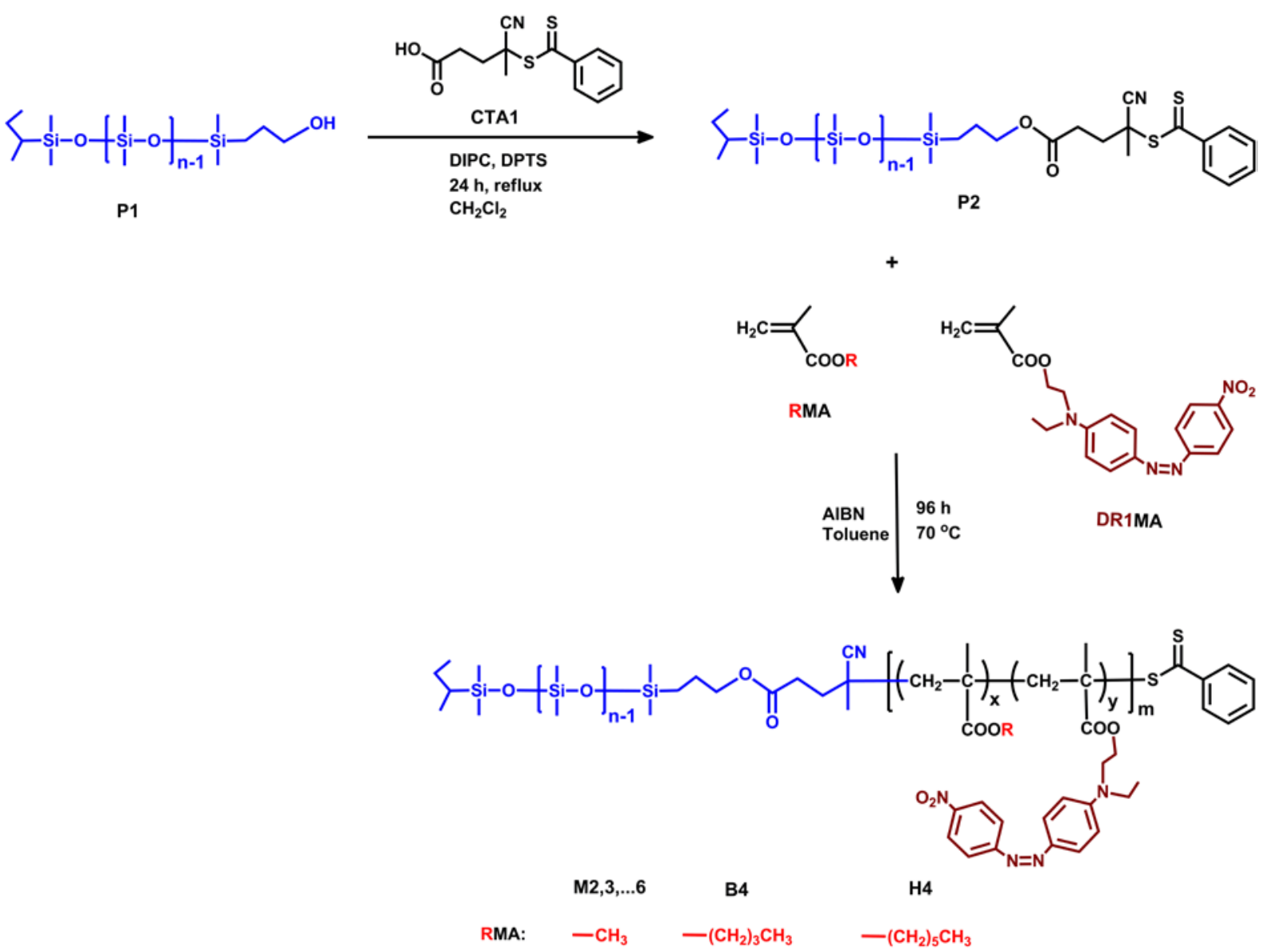

Scheme 1. Synthetic pathway used for the synthesis of the PDMS- $b-P(D R 1 M A-c o-R M A)$ BCPs.

Firstly, a macro-chain transfer agent (CTA) was devised through the esterification reaction of a commercial available carboxylic acid functionalized CTA with a mono-carbinol PDMS. The anionic polymerization of hexamethylcyclotrisiloxane (D3) using sec-butyllithium as initiator and chlorodimethylsilane as terminating agent was first performed for the synthesis of a mono-hydride terminated PDMS. The resulting homopolymer has a molecular weight close to $10 \mathrm{~kg} / \mathrm{mol}$ according to the end-group analysis given by the proton nuclear magnetic resonance $\left({ }^{1} \mathrm{H}-\mathrm{NMR}\right)$ spectrum shown in Figure S1. The - $\left(\mathrm{CH}_{3}\right)_{2} \mathrm{SiH}$ chain-end functionality of this precursor is close 
to unity, as determined by comparing the integration value for the methine proton from the secbutyl groups $\left(1 \mathrm{H}_{\mathrm{a}}\right)$ at $0.5-0.6 \mathrm{ppm}$ and for the hydrosilyl proton $\left(1 \mathrm{H}_{\mathrm{e}}\right)$ at $4.7 \mathrm{ppm}$. The hydrosilylation of the mono-hydride terminated PDMS with allyl alcohol employing a Pt catalyst leads to the mono-carbinol PDMS. The $-\mathrm{CH}_{2} \mathrm{OH}$ chain-end functionality was determined around 95\% from the comparison between the integration value for the methine proton of the sec-butyl groups overlapped with $-\mathrm{Si}-\mathrm{CH}_{2}-$ protons $\left(1 \mathrm{H}_{\mathrm{c}}+2 \mathrm{H}_{\mathrm{e}}\right)$ at $0.5-0.6 \mathrm{ppm}$ and the integration value for the $-\mathrm{CH}_{2}-$ protons next to $-\mathrm{OH}$ at $3.6 \mathrm{ppm}\left(2 \mathrm{H}_{\mathrm{g}}\right)$ (see Figure S2). A dithiobenzoate CTA was chosen for the polymerization of DR1MA due to its success in the RAFT polymerization of azomethacrylates. $^{30,31,39,40}$ The corresponding PDMS macro-CTA (P2) was synthesized by esterification with a commercial available carboxylic acid functionalized dithiobenzoate CTA, as shown in Scheme 1. A modified Steglich esterification method, which employs $N, N^{\prime}-$ diisopropylcarbodiimide (DIPC) and 4-(dimethylamino)pyridinium p-toluenesulfonate (DPTS) as catalysts, was used to attain a quantitative conversion as noted by the downfield shift of the peak at $3.6 \mathrm{ppm}$ attributed to the $-\mathrm{CH}_{2}-$ vicinal to $-\mathrm{OH}\left(2 \mathrm{H}_{\mathrm{d}}\right)$ in $\mathrm{P} 1$ to $4.05 \mathrm{ppm}\left(2 \mathrm{H}_{\mathrm{d}^{\prime}}\right)$ in $\mathrm{P} 2 .{ }^{41} \mathrm{~A}$ high degree of functionalization for P2 of $\sim 84 \%$ was shown by end-group analysis using ${ }^{1} \mathrm{H}-\mathrm{NMR}$ (see Figure S3). This homopolymer has a molecular weight close to $10 \mathrm{~kg} / \mathrm{mol}$ with a dispersity of 1.08, according to the size exclusion chromatography (SEC) trace performed in toluene using PDMS standards (see Figure S4). 


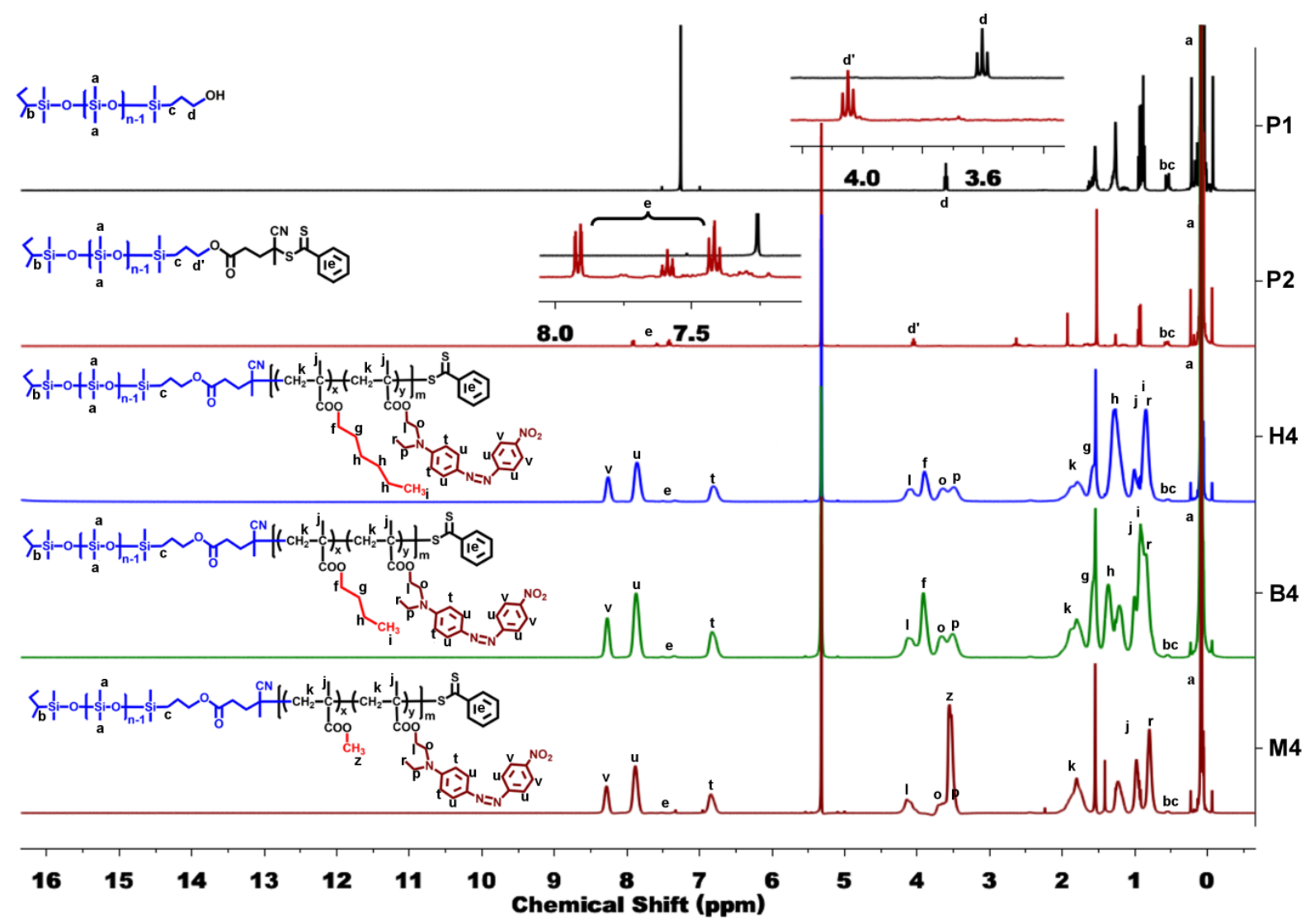

Figure 1. Overlaid ${ }^{1} \mathrm{H}-\mathrm{NMR}$ spectra corresponding to the mono-carbinol PDMS (P1) in $\mathrm{CDCl}_{3}$, the PDMS macro-CTA (P2) and typical BCPs in $\mathrm{CD}_{2} \mathrm{Cl}_{2}$.

The RAFT copolymerization of DR1MA and RMA was performed in toluene at $70^{\circ} \mathrm{C}$ using various monomers feed compositions (see Table 1) and a constant molar ratio [PDMSCTA $]:[\mathrm{AIBN}]=1: 0.25$. Considering the high tendency of DR1MA and RMA towards copolymerization and homopolymerization, respectively, ${ }^{42,43}$ the monomer feeds were adjusted as regards to the targeted BCP compositions while the PDMS macro-CTA was kept constant at 20 wt.\% in the total feed mixture. The chemical structure of the obtained BCPs was confirmed by the characteristic resonance signals on the ${ }^{1} \mathrm{H}-\mathrm{NMR}$ spectra and the assignment for some representative BCPs is given in Figure 1 (see Experimental Section for details). The molecular weight of the obtained BCPs was also determined by ${ }^{1} \mathrm{H}-\mathrm{NMR}$ using the PDMS block as reference while the DR1 content embedded in the side-chain of the BCPs was obtained by using the 
integration values for the aromatic protons at 6.9-8.3 ppm $\left(2 \mathrm{H}_{v}, 4 \mathrm{H}_{\mathrm{u}}\right.$ and $2 \mathrm{H}_{\mathrm{t}}$ from Figure 1) (see Supporting Information for details). The macromolecular characteristics of the synthesized BCPs as determined by SEC and ${ }^{1} \mathrm{H}-\mathrm{NMR}$ analyses are summarized in Table 1 (see also Figures S511). It is noteworthy that the SEC traces obtained by UV detection gives similar chromatograms than the ones acquired from the RI detector, confirming a PDMS chain extension with an UVabsorbing DR1MA block.

Table 1. Macromolecular characteristics of the synthesized polymers.

\begin{tabular}{|c|ccc|ccc|ccc|c|c|}
\hline Code & \multicolumn{3}{|c|}{$\begin{array}{c}\text { Feed composition } \\
\text { wt. \% }\end{array}$} & \multicolumn{3}{|c|}{$\begin{array}{c}\text { Polymer composition } \\
\text { wt. \% }\end{array}$} & \multicolumn{3}{c|}{$\begin{array}{c}\mathbf{M}_{\mathbf{n}} \\
\mathbf{k g} / \mathbf{m o l}\end{array}$} & $\mathbf{\Xi}^{\mathbf{3}}$ & $\mathbf{T}^{\mathbf{T}}{ }^{\mathbf{}} \mathbf{C}$ \\
\hline & DMS & RMA & DR1MA & DMS & RMA & DR1MA & Theo. & NMR $^{1}$ & SEC $^{3}$ & & \\
\hline P1 & n/a & n/a & n/a & 100 & n/a & n/a & 11.6 & 10.0 & 9.7 & 1.08 & n.d. \\
P2 & n/a & n/a & n/a & 100 & n/a & n/a & 10.0 & 11.3 & 9.5 & 1.08 & n.d. \\
M1 & 20 & 80 & 0 & 17 & 83 & 0 & 51.7 & 57.7 & 40.2 & 1.13 & 123 \\
M2 & 20 & 72 & 8 & 27 & 63 & 10 & 51.7 & 37.5 & 34.3 & 1.07 & 122 \\
M3 & 20 & 60 & 20 & 30 & 49 & 21 & 51.7 & 33.8 & 29.8 & 1.08 & 123 \\
M4 & 20 & 40 & 40 & 38 & 22 & 40 & 51.7 & 26.0 & 19.9 & 1.10 & 125 \\
B4 & 20 & 40 & 40 & 32 & 32 & 36 & 51.7 & 31.4 & 20.2 & 1.13 & 84 \\
H4 & 20 & 40 & 40 & 31 & 34 & 35 & 51.7 & 31.8 & 17.7 & 1.18 & 60 \\
\hline
\end{tabular}

${ }^{1}$ RMA: MMA, $n$ BMA or $n$ HMA. ${ }^{2}$ Determined by ${ }^{1} \mathrm{H}-\mathrm{NMR} .{ }^{3} \mathrm{SEC}$ in THF $\left(40^{\circ} \mathrm{C}\right.$, PS calibration $)$ for BCPs and in toluene for P1 and P2 $\left(40^{\circ} \mathrm{C}\right.$, PDMS calibration). ${ }^{4} \mathrm{Tg}$ value for the P(DR1MAco-RMA) block as determined by DSC. (n/a: not applicable and n.d.: not determined)

The BCPs were also characterized by differential scanning calorimetry (DSC) in order to study their thermal behaviors and the DSC traces are presented in Figure S12. The glass transition ( $\left.T_{\mathrm{g}}\right)$ of the $\mathrm{P}(\mathrm{DR} 1 \mathrm{MA}-\mathrm{co}-\mathrm{RMA})$ block is noticed at around $122^{\circ} \mathrm{C}$ for $\mathrm{P}(\mathrm{DR} 1 \mathrm{MA}-\mathrm{co}-\mathrm{MMA}), 84^{\circ} \mathrm{C}$ for P(DR1MA-co-nBMA) and $60^{\circ} \mathrm{C}$ for $\mathrm{P}(\mathrm{DR} 1 \mathrm{MA}-\mathrm{co}-\mathrm{nHMA})$, confirming the plasticizing effect of the $n$-butyl and $n$-hexyl moieties in B4 and H4. Interestingly, the characteristic melting 
temperature, $T_{\mathrm{m}}$, of the PDMS block of $-48^{\circ} \mathrm{C}$ was only noticed for $\mathrm{M} 4$ as it contains enough PDMS to undergo a cold crystallization. The embedment of the UV-Vis absorbing DR1 moieties in the BCP architecture was also confirmed by UV-Vis absorption spectroscopy in THF at $25^{\circ} \mathrm{C}$ (see Figure S13) with the characteristic absorptions of the DR1 moieties, i.e., a strong absorption band at $285 \mathrm{~nm}$ attributed to the $\pi-\pi^{*}$ transitions of the aromatic rings and the maximum at 470 $\mathrm{nm}$ corresponding to the $\mathrm{n}-\pi^{*}$ transitions of nitrogen lone pairs. ${ }^{27}$

\section{Phase behavior of amorphous azo-containing block copolymers in bulk and thin films.} Synchrotron small angle X-ray scattering (SAXS) profiles are presented in Figure 2 for typical PDMS-b-P(DR1MA-co-RMA) BCPs. By increasing the PDMS weight fraction from 0.17 to 0.38 , the usual sequence of morphologies occurring for microphase-separated diblock copolymers in bulk is retrieved. The SAXS reflections for M1 could be tentatively asserted to PDMS spheres arranged in a body-centered cubic (BCC) lattice having a period, $p$, of $\sim 36.4 \mathrm{~nm}$ since the firstorder peak, $q^{*}$, is located at $0.21 \mathrm{~nm}^{-1}\left(p=\left(2 \pi / q^{*}\right)(3 / 2)^{1 / 2}\right)$. The SAXS profile also shows two broad maxima located at 0.5 and $0.78 \mathrm{~nm}^{-1}$ due to the intra-particle interference of the single spherical domains. From the peak position, $q_{\mathrm{i}}$, of the $i$ th maximum form factor, the average sphere radius $R_{\text {sph }}$ is calculated to be $\sim 11.6 \mathrm{~nm}$ (according to $q_{i} R_{\text {sph }}=5.765,9.111 \ldots$ for $i=1,2 \ldots$ ). It should be noted, however, that the BCC lattice should have a considerable distortion as evident from the SAXS profile exhibiting only a first-order scattering from the lattice. Increasing the PDMS weight fraction within the M2 and M3 BCPs leads to hexagonally-close packed (HCP) cylindrical nanostructures. This is particularly unambiguous for M3 as the higher-order peaks appear at $q / q^{*}=1,4^{1 / 2}, 7^{1 / 2}, 9^{1 / 2}, 12^{1 / 2}, 13^{1 / 2}, 16^{1 / 2}$ in accordance with a hexagonal array ( $p 6 m m$ symmetry) having a period of $35.4 \mathrm{~nm}\left(p=\left(2 \pi / q^{*}\right)(4 / 3)^{1 / 2}\right.$ where $\left.q^{*}=0.205 \mathrm{~nm}^{-1}\right)$. The second 
order scattering extinction observed on the M3 SAXS profile is related to the cylinder form factor for a cylinder radius, $R_{\text {cyl }}$, of $\sim 11 \mathrm{~nm}$ which confirm that the PDMS composition, $\phi_{\text {PDMS }}$, is about $0.3\left(R_{\mathrm{cyl}}=p\left(\left(\phi_{\mathrm{PDMS}} \sqrt{3}\right) / 2 \pi\right)^{1 / 2}\right)$. For $\phi_{P D M S} \sim 0.38$, the SAXS profile shows a first-order peak at 0.22 $\mathrm{nm}^{-1}$ and higher-order peaks located at $q / q^{*}=1,2,3,4,5,6$ which indicates that M4 is arranged into a lamellar structure having a period of $\sim 28.6 \mathrm{~nm}\left(p=2 \pi / q^{*}\right)$. By varying the chemical nature of the co-monomer in the P(DR1MA-co-RMA) block, SAXS reflections for both B4 and H4 samples are consistent with a HCP cylinder morphology $\left(p_{\mathrm{B} 4}=28.6 \mathrm{~nm}\right.$ and $\left.p_{\mathrm{H} 4}=27.6 \mathrm{~nm}\right)$.

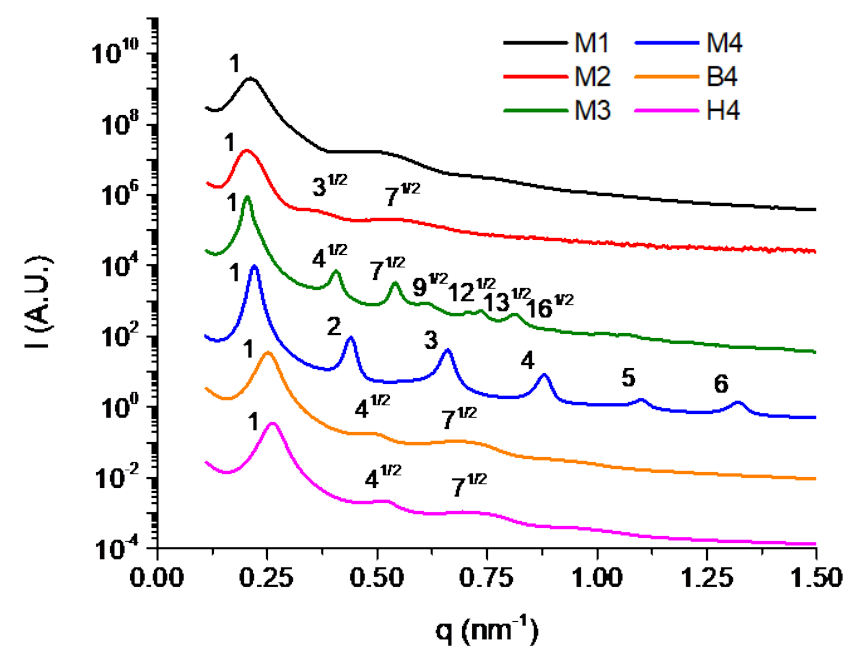

Figure 2. Synchrotron SAXS profiles of different PDMS-b-P(DR1MA-co-RMA) samples obtained at $180^{\circ} \mathrm{C}$. Curves have been shifted vertically for clarity.

Nanostructures formed by microphase-separated BCP thin films were also studied using solvent vapor annealing (SVA) ${ }^{44}$ For that purpose, $170 \mathrm{~nm}$ thick PDMS-b-P(DR1MA-co-RMA) films, deposited on silicon substrates from 3 wt. \% solutions (tetrahydrofuran/propylene glycol monomethyl ether acetate, THF/PGMEA: 70/30), were exposed to a chloroform $\left(\mathrm{CHCl}_{3}\right)$ vapor in order to promote the self-assembly (SA) of the BCP chains. The atomic force microscopy (AFM) image contrast was enhanced by treating the PDMS- $b$-P(DR1MA-co-RMA) thin films with a $\mathrm{CF}_{4} / \mathrm{O}_{2}$ reactive ion etch (RIE) plasma (plasma conditions are $40 \mathrm{~W}, 17 \mathrm{sccm} \mathrm{CF} 4$ and $3 \mathrm{sccm} \mathrm{O}$, 
45 s) to remove the PDMS surface wetting layer having a typical thickness of $\sim 7 \mathrm{~nm}$. Figure 3 shows AFM phase images for selected materials (M1, M2 and M3) having different P(DR1MAco-MMA) compositions. The AFM phase image presented in Figure 3a shows a solvent-annealed M1 thin film in which a HCP arrangement of PDMS spheres having a period of $29.8 \mathrm{~nm}$, extracted from the AFM fast Fourier transform (FFT), can be observed, which differs from the BCC phase observed in bulk (see Figure 2). Such behavior is in accordance with previous studies demonstrating for spherical BCP features that the BCC phase is preferred in bulk while a HCP arrangement with the close-packed planes oriented parallel to the substrate are energetically more stable in thin films. ${ }^{45,46}$ An in-plane cylindrical structure is produced from both solvent-annealed (3h, $\mathrm{CHCl}_{3}$ ) M2 and M3 thin films as shown on the AFM phase images presented in Figures 3b,c. Cylindrical repeat periods of $\sim 26.7 \mathrm{~nm}$ and $\sim 28.8 \mathrm{~nm}$ are measured from the M2 and M3 thin films, respectively, in agreement with the bulk periodicity obtained by SAXS.
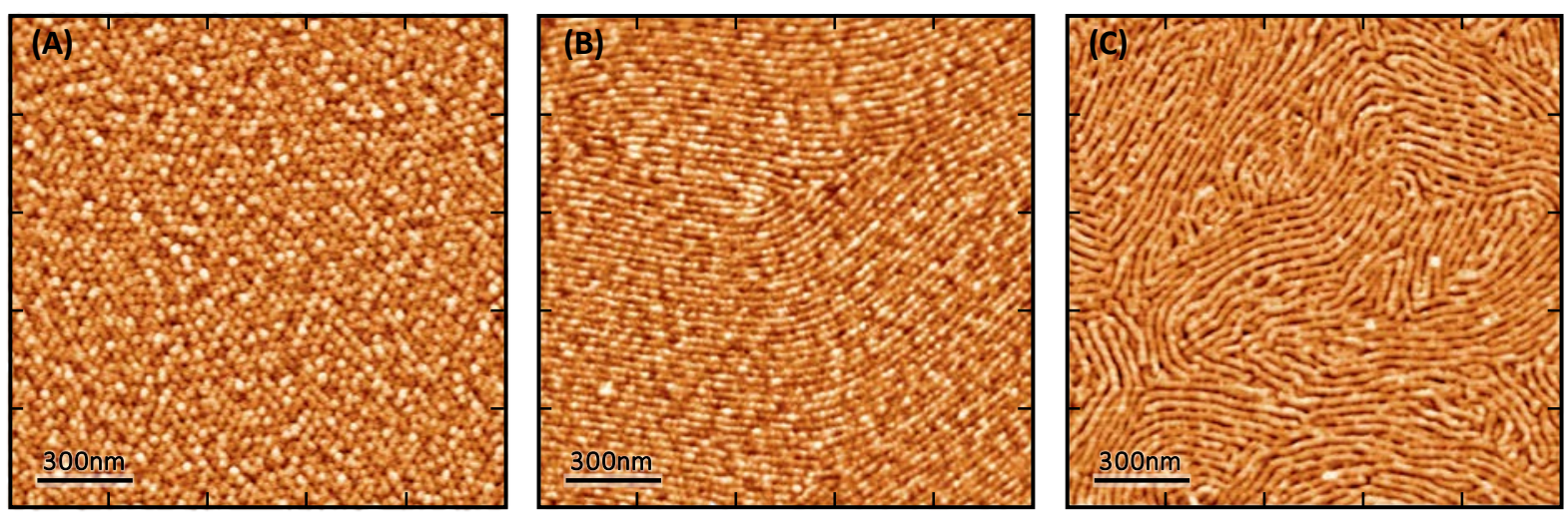

Figure 3. (1.5 x $1.5 \mu \mathrm{m})$ AFM phase views of solvent-annealed (3 h, $\left.\mathrm{CHCl}_{3}\right)$ PDMS- $b$-P(DR1MAco-MMA) thin films with different PDMS compositions treated by a $\mathrm{CF}_{4} / \mathrm{O}_{2}$ RIE plasma: a) 0.17 for M1, b) 0.27 for M2 and c) 0.3 for M3. A HCP array of PDMS spheres is produced from M1 $\left(p_{\mathrm{M} 1}=29.8 \mathrm{~nm}\right)$ while an in-plane cylindrical structure is observed from both $\mathrm{M} 2\left(p_{2}=26.7 \mathrm{~nm}\right)$ and M3 $\left(p_{\mathrm{M} 3}=28.8 \mathrm{~nm}\right)$ thin films.

Interestingly the lamellar structure revealed by SAXS for M4 is not retrieved in thin film configuration as the AFM phase image presented in Figure 4a is rather consistent with an in-plane 
cylindrical structure having a period of $\sim 24.9 \mathrm{~nm}$. This is likely related to the high selectivity of $\mathrm{CHCl}_{3}$ toward the methacrylate block (as suggested by the Hildebrand solubility parameter values: $\delta_{\text {PDMS }}=14.9 \mathrm{MPa}^{1 / 2}, \delta_{\mathrm{PMMA}}=19 \mathrm{MPa}^{1 / 2}$ and $\left.\delta_{\mathrm{CHCl}}=18.7 \mathrm{MPa}^{1 / 2)}\right)^{47}$ which modified the overall BCP composition by selectively swelling the methacrylate domains during the SVA treatment. Additionally, the formation of a PDMS wetting layer at the air surface, which (i) artificially depletes the PDMS fraction in the self-assembled layer and (ii) imposes an in-plane orientation of the BCP features, should also be taken into account as a driving force that favors the microphaseseparation of the BCP chains into an in-plane cylindrical structure. To further probe the in-depth structure of the M4 BCP thin film, grazing incidence small angle X-ray scattering (GISAXS) experiments were performed and the 2D GISAXS pattern presented in Figure S14 supports the morphological assignment deduced from AFM, as the observed diffraction features are consistent with hexagonally-structured domains aligned with their $\{10\}$ planes parallel to the film surface. ${ }^{48-}$ ${ }^{50}$ In contrast, similar morphologies are retrieved for the B4 and H4 samples since in-plane PDMS cylinders are formed within the solvent-annealed BCP thin films (see Figures $\mathbf{4 b}, \mathbf{c}$ ).
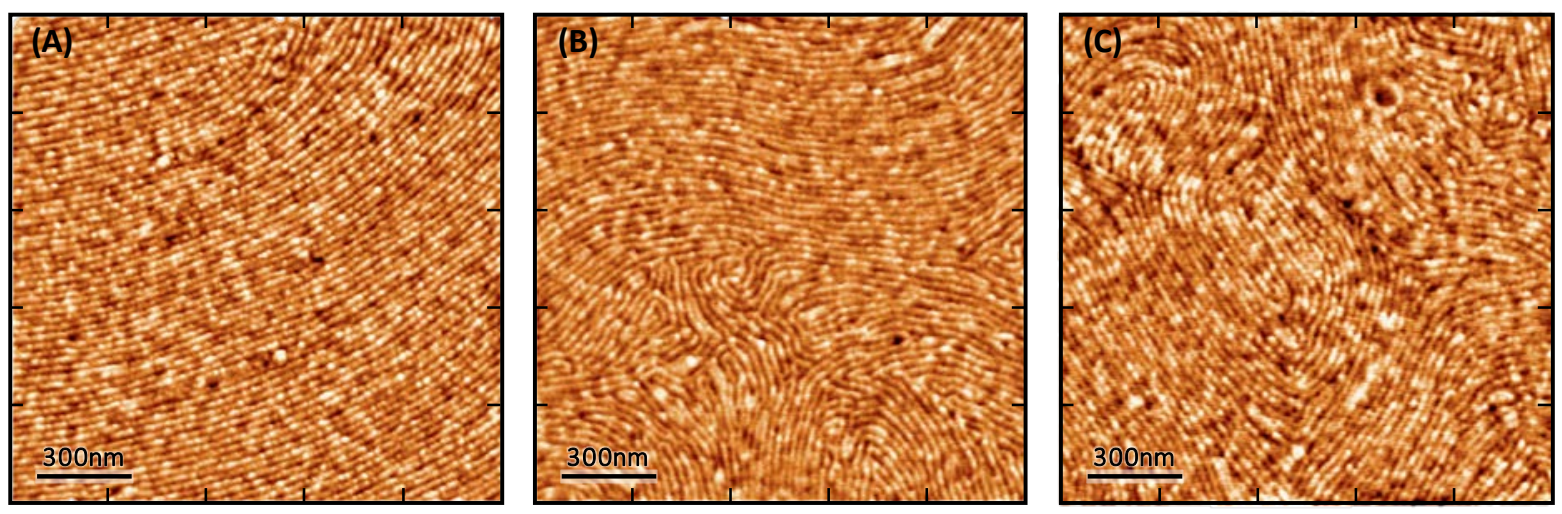

Figure 4. (1.5 x $1.5 \mu \mathrm{m}$ ) AFM phase views of solvent-annealed (3 h, $\left.\mathrm{CHCl}_{3}\right)$ PDMS- $b$-P(DR1MAco-RMA)) thin films with chemically distinct acrylate co-monomers treated by a $\mathrm{CF}_{4} / \mathrm{O}_{2} \mathrm{RIE}$ plasma: a) MMA (M4), b) $n \mathrm{BMA}$ (B4) and c) $n \mathrm{HMA}(\mathrm{H} 4)$. An in-plane cylinder structure is observed for the M4 $\left(p_{\mathrm{M} 4}=24.9 \mathrm{~nm}\right), \mathrm{B} 4\left(p_{\mathrm{B} 4}=26.7 \mathrm{~nm}\right)$ and M3 $\left(p_{\mathrm{H} 4}=25.8 \mathrm{~nm}\right)$ thin films. 
To know more about the effect on the azo-dye content on the photo-induced motion of azocontaining BCP chains, sinusoidal patterns were inscribed into several PDMS-b-P(DR1MA-coMMA) layers having different amounts of DR1MA units (0 to $40 \mathrm{wt}$.\%) for the same exposure time. For that purpose, different $170 \mathrm{~nm}$ thick PDMS-b-P(DR1MA-co-MMA) layers, spin-coated from a 3 wt. \% solutions (THF/PGEMA: 70/30), were exposed 5 min to a $p$-polarized laser beam ( $\mathrm{P}=250 \mathrm{~mW} / \mathrm{cm}^{2}$ and $\lambda_{w}=532 \mathrm{~nm}$ where $\lambda_{w}$ is the writing wavelength) mounted on a Lloyd's mirror interferometer set-up to generate the SRG inscription. ${ }^{10}$ Figure 5a shows that the dependence of the surface modulation amplitude (SMA), defined as the peak-to-valley distance, does not vary linearly with the number of DR1MA units since a threshold effect related to low azo-dye contents should be taken into account for the shape of the curve. ${ }^{51}$ For instance, the AFM topographic image presented in Figure $5 \mathbf{b}$ shows the sinusoidal pattern inscribed into a $170 \mathrm{~nm}$ thick M4 layer having a DR1MA content of 40 wt. \%. For such sample, 5 min treatment enables to produce a well-defined sinusoidal pattern over large area having a period of $\sim 357 \mathrm{~nm}$ and a SMA of $\sim 60 \mathrm{~nm}$ (see Figure 5c).
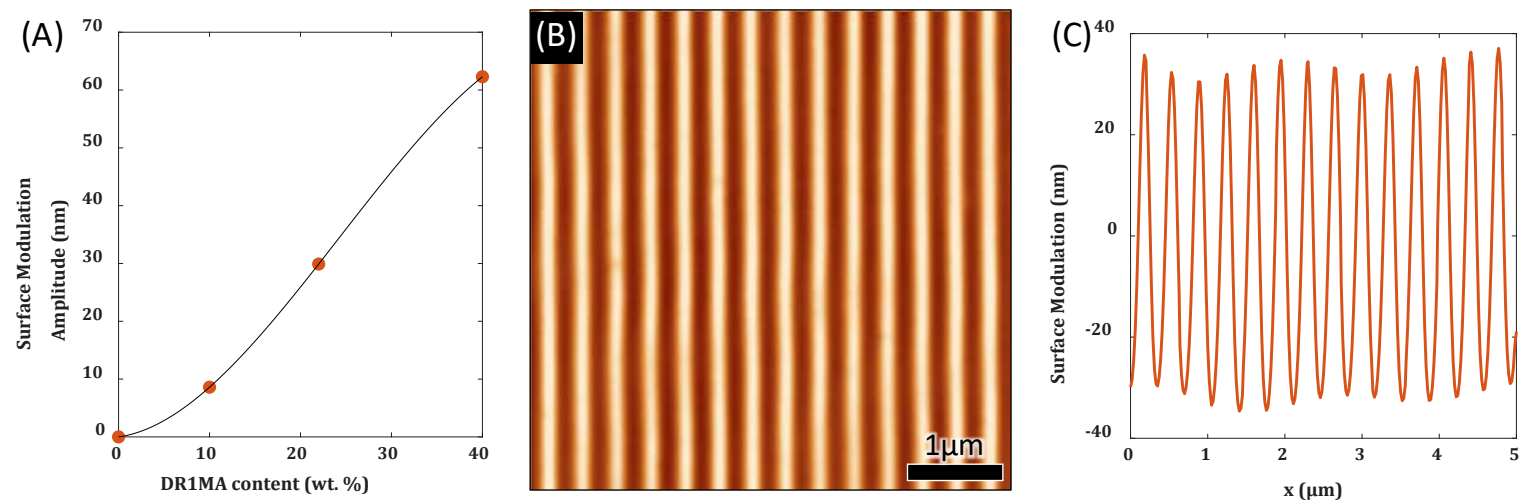

Figure 5. a) SMA of different PDMS- $b-\mathrm{P}(\mathrm{DR} 1 \mathrm{MA}-\mathrm{co}-\mathrm{MMA})$ layers as a function of their DR1MA content (wt. \%) measured after an exposition to a $p$-polarized laser beam ( $\mathrm{P}=250$ $\mathrm{mW} / \mathrm{cm}^{2}$ and $\lambda_{w}=532 \mathrm{~nm}$ ) during $5 \mathrm{~min}$ (the continuous line is used to guide the eye). b) ( $5 \times 5$ $\mu \mathrm{m})$ AFM topographical view of a photo-inscribed sinusoidal SRG into a $170 \mathrm{~nm}$ thick M4 layer 
using a Lloyd's mirror interferometer set-up. c) height profile extracted from the topographical AFM image presented in b).

The combination of the SRG and SVA processes was further investigated to better apprehend the potential synergy between the BCP self-assembly and the SRG photoinscription in order to manufacture long-range ordered BCP features aligned along an arbitrary direction. In this regard, two experimental methodologies were applied to the BCP layers as depicted in the Scheme 2: i) the BCP layer is self-assembled by SVA prior to the SRG inscription; or ii) the sinusoidal SRG is inscribed into the as-cast (disordered) BCP layer prior to generate the nanodomain formation by SVA.

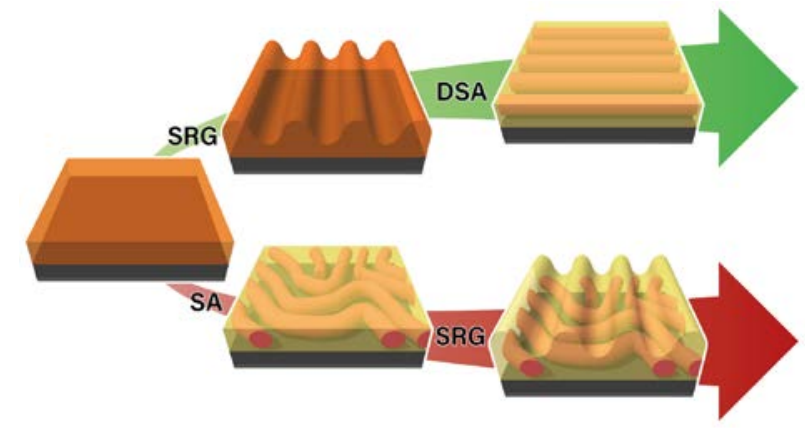

Scheme 2. Schematic illustration of the two different methods used in this work to produce laterally-aligned BCP features from as-cast (disordered) DR1MA-containing BCP thin films: (top panel) maximization of the orthogonal alignment of the DR1MA-dyes during the SRG inscription into the disordered BCP layer, which subsequently induces the DSA of BCPs during the SVA process, and (bottom panel) SA of BCP chains by SVA followed by a SRG inscription, which lacks the preferential alignment of the PDMS cylinders.

Both methods were applied to 170 nm thick M4 layers since well-defined in-plane PDMS cylinders have been produced by SVA (see Figure 4a) and also a large surface modulation amplitude was achieved thanks to the high content in DR1MA-dye moieties (see Figure 5). Importantly, the ascast $170 \mathrm{~nm}$ thick M4 layers are disordered after their deposition by spin-coating as shown on the AFM topographic image presented Figure S15 where the 2D-FFT is dominated by noise (no- 
characteristic length scale). Therefore, the M4 layers have to be treated by SVA to generate the formation of the cylindrical nanodomains. The AFM topographic image presented in Figure 6 shows that, although a sinusoidal SRG was readily inscribed into the solvent-annealed ( $3 \mathrm{~h}, \mathrm{CHCl}_{3}$ ) M4 layer (SMA $30 \mathrm{~nm}$ ) after an exposure time of $30 \mathrm{~min}$, an alignment of the PDMS cylinders along a preferential direction was not effective as previously reported from amorphous azocontaining BCP thin film. ${ }^{41}$
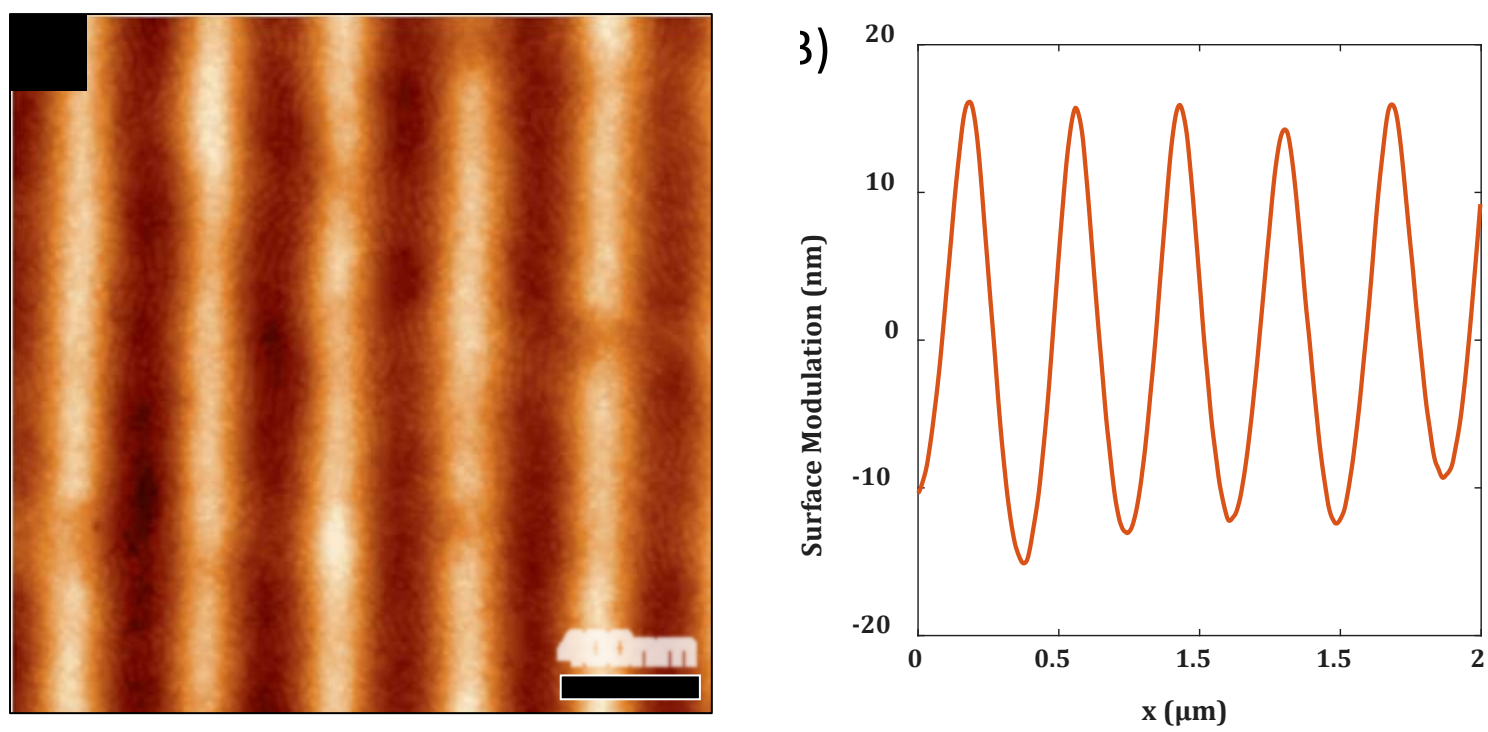

Figure 6. a) $(2 \times 2 \mu \mathrm{m})$ AFM topographic view of a solvent-annealed (3h, $\left.\mathrm{CHCl}_{3}\right) \mathrm{M} 4$ layer exposed to a $p$-polarized beam laser $\left(\lambda_{\mathrm{w}}=532 \mathrm{~nm}, \mathrm{P}=30 \mathrm{~mW} \cdot \mathrm{cm}^{-2}\right)$ beam during $30 \mathrm{~min}$. Poorlyordered PDMS cylinders are produced within the M4 layer having a periodic roughness induced by the SRG inscription. b) The AFM topographic profile reveals that the SRG pattern adopts a sinusoidal shape with a period of $\sim 357 \mathrm{~nm}$ and a SMA of $\sim 30 \mathrm{~nm}$.

Conversely, laterally-ordered in-plane cylinders aligned orthogonal to the polarization light plane were produced from as-cast photo-inscribed (30 min) M4 layers treated by a solvent vapor (3h, $\mathrm{CHCl}_{3}$ ) (see Figure 7). The AFM topographic and phase images presented in Figure 7a,b show long-range ordered in-plane PDMS cylinders over $5 \times 5 \mu \mathrm{m}^{2}$ as attested by the presence of two spots on the 2D-FFTs (see insets of Figure 7a,b). It is noteworthy that the periodic roughness 
profile (SMA > $100 \mathrm{~nm}$ ) observed after the SRG inscription into the disordered M4 layer vanished during the SVA process (see Figure S16). Indeed, a root mean square roughness, $R_{\mathrm{rms}}$, of $\sim 10 \mathrm{~nm}$ was measured from the AFM topographical image presented in Figure 7a after exposing the M4 layer to a vapor treatment $\left(3 \mathrm{~h}, \mathrm{CHCl}_{3}\right)$. This phenomenon is obviously due the enhanced diffusion of the BCP chains swelled by the $\mathrm{CHCl}_{3}$ vapor during the SVA process, en route to form the inplane PDMS cylinders (see also Figure 7c).
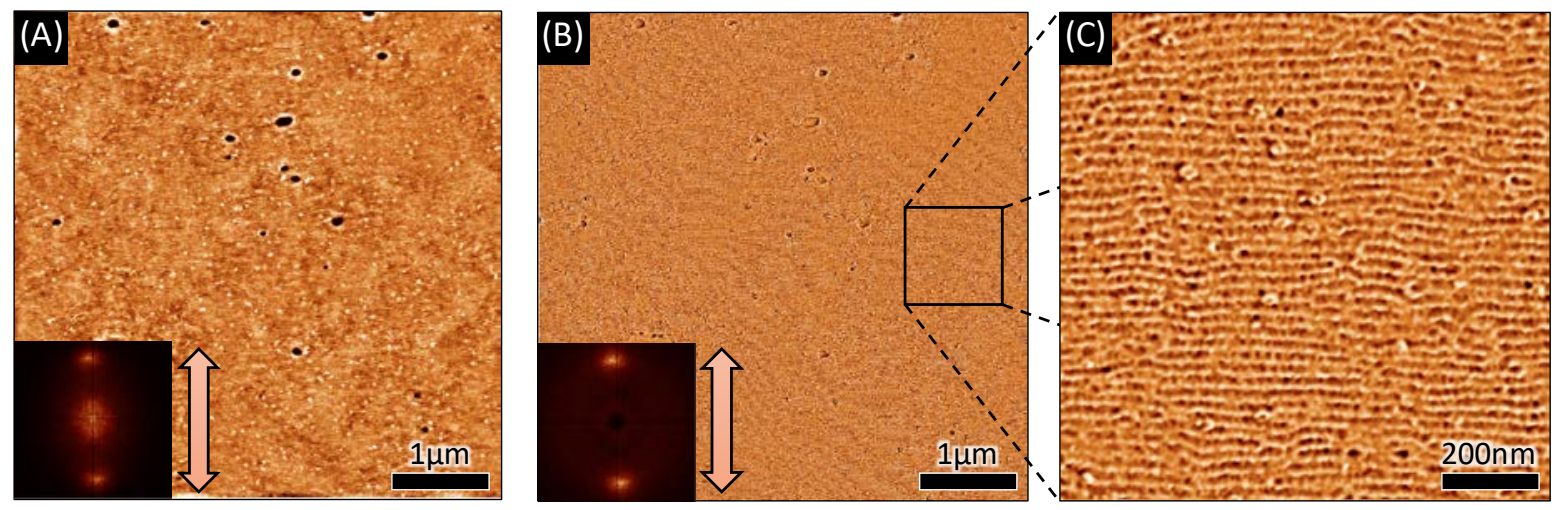

Figure 7. (5 x $5 \mu \mathrm{m}$ ) AFM (a) topographical and (b) phase views of a solvent-annealed ( $3 \mathrm{~h}$, $\mathrm{CHCl}_{3}$ ) M4 layer in which a SRG pattern was previously inscribed (the arrows indicate the initial trench long axis). Under such conditions, in-plane cylindrical domains aligned orthogonal to the initial trench long axis are produced as attested by the sharp azimuthal distribution of the 2D-FFT spots (see insets). (c) Magnified AFM phase view of the cylindrical domains aligned orthogonal to the initial trench long axis.

Overall, such results indicate that the alignment of the DR1MA-dyes upon a p-polarized beam during 30 min is more effective within an as-cast (disordered) M4 layer than the one occurring within its microphase-separated homologue as indirectly supported by the significant difference in the SMA values $\left(\mathrm{SMA}_{\text {disoredred,30min }}>100 \mathrm{~nm}\right.$ and $\left.\mathrm{SMA}_{\text {ordered,30min }}=30 \mathrm{~nm}\right)$. We believe that the effective pre-alignment of the DR1MA dyes within the disordered M4 layers directs the self-assembly of the BCP chains when exposed to a $\mathrm{CHCl}_{3}$ vapor to finally achieve laterally-ordered in-plane PDMS cylinders oriented along an arbitrary direction. 


\section{Conclusion.}

In summary, a synthetic approach was developed to prepare well-defined DR1MA-based BCPs giving access to photo-responsive materials with a dye loading up to 40 wt.\%. By varying the weight fraction of the azo-containing block, various self-assembled structures were identified both in bulk and in thin film while SRG inscription into these BCP layers led to a typical sinusoidal surface modulation pattern. The combination of the SRG photo-inscription with a SVA treatment was further investigated to better apprehend the potential synergy between these two processes towards the fabrication of long-range ordered BCP features aligned along an arbitrary direction. Interestingly, laterally-ordered in-plane Si-containing nanoscale cylinders were demonstrated from a specific process combination. Such surfaces having highly-ordered silica precursor domainforming line and space patterns can be used as guides for the long range order nanofabrication of features (e.g., dots, holes and pillars) derived from the BCP self-assembly processes. ${ }^{36,38,52-54}$ 


\section{Experimental section}

Materials. Toluene (99.5\%, Sigma Aldrich) was distilled first from $\mathrm{CaH}_{2}$ and then from living polystyrene. Dichloromethane (99.9\%, Sigma Aldrich) was used as it is from a drying columns system. n-Hexyl methacrylate (nHMA, 97\%, TCI), n-butyl methacrylate (nBMA, 99\%, Sigma Aldrich) and methyl methacrylate (MMA, 99\%, Acros Organics) were first distilled from $\mathrm{CaH}_{2}$ and then distilled over trioctylaluminium (25\% solution in hexane, Sigma Aldrich). 4(Dimethylamino) pyridinium p-toluenesulfonate (DPTS) was in-house synthesized as previously reported. ${ }^{41}$ Azobis(isobutyronitrile) (AIBN, 98\%, Acros Organics) was recrystallized from methanol and dried at room temperature under vacuum prior to use. Tetrahydrofuran (THF, 99.9\%, Sigma Aldrich), Disperse Red 1 methacrylate (DR1MA, 95\%, Sigma Aldrich), $N, N^{\prime}-$ diisopropylcarbodiimide (DIPC, 99\%, Sigma Aldrich), 2-propanol (99.5\%, Sigma Aldrich), acetonitrile (99\%, Fisher), 4-dimethylaminopyridine (DMAP, 99\%, Acros Organics), 4toluenesulfonic acid (pTSA, 99\%, Alfa Aesar) and 4-cyano-4-(phenylcarbonothioylthio)pentanoic acid (CTA, 97\%, Sigma Aldrich) were used as received.

Self-assembly of PDMS-b-P(DR1MA-co-RMA) thin films. PDMS- $b$-P(DR1MA-co-RMA) thin films were spin-coated (2 krpm) using a $3 \mathrm{wt} \%$ copolymer solution in THF/PGMEA: 70-30. The self-assembly of PDMS- $b$-P(DR1MA-co-RMA) thin films was promoted by exposing samples during 3h to a continuous stream of a $\mathrm{CHCl}_{3}$ vapor produced by bubbling nitrogen gas through the liquid solvent, so that the solvent vapor consisted of $32 \mathrm{sccm} \mathrm{CHCl}_{3}$ and $8 \mathrm{sccm} \mathrm{N}_{2}$ (total 40 sccm). ${ }^{51}$ In-situ measurements of the BCP layer thicknesses during the SVA treatment were estimated through the quartz SVA chamber lid using a Filmetrics reflectometer apparatus and the BCP layers reached a plateau for a thickness variation of $\sim 150 \%$. The morphology of the solvent- 
annealed PDMS-b-P(DR1MA-co-RMA) thin films was frozen by quickly removing the lid of the chamber.

\section{Characterization methods}

Proton nuclear magnetic resonance $\left({ }^{1}\right.$ H-NMR) spectra were all recorded using a liquid-state $400 \mathrm{MHz}$ NMR spectrometer (Bruker AVANCE I) with $5 \mathrm{~mm}$ BBFO probe in the appropriate deuterated solvent.

Size exclusion chromatography (SEC) traces were acquired from a PL-GPC 50 Plus (Agilent Technologies) integrated system with RI and UV detectors using a three column set of TSK gel TOSOH (G4000HXL, G3000HXL, G2000HXL with pore sizes of 20, 75 and $200 \AA$ respectively, connected in series) at $40^{\circ} \mathrm{C}$. The calibration was performed with PS standards for SEC traces using THF as eluent ( $1 \mathrm{~mL} / \mathrm{min})$ while PDMS standards were used for SEC traces using toluene as eluent $(0.8 \mathrm{~mL} / \mathrm{min})$. Trichlorobenzene (TCB) was used in both cases as a flow marker.

Differential scanning calorimetry (DSC) measurements were performed using a Q100 apparatus from TA Instruments. DSC experiments were carried out in aluminum sealed pans containing 5 to $10 \mathrm{mg}$ of sample. Each sample was first heated up to $150^{\circ} \mathrm{C}$ at $10^{\circ} \mathrm{C} / \mathrm{min}$ and then the heating was kept constant at this temperature for 10 min in order to delete the thermal history. Further, the sample was cooled down to $-80^{\circ} \mathrm{C}$ at $10^{\circ} \mathrm{C} / \mathrm{min}$ followed by heating up to $250^{\circ} \mathrm{C}$ at $10^{\circ} \mathrm{C} / \mathrm{min}$.

Ultraviolet-visible spectroscopy (UV-Vis) was performed on a UV-3600 spectrophotometer from Shimadzu.

Atomic Force Microscopy (AFM) characterizations were performed on a Dimension FastScan setup, Bruker in tapping mode to characterize the surface morphology of BCP thin films. Silicon 
cantilevers (FastScan-A) with a typical tip radius of $\approx 5 \mathrm{~nm}$ were used. The resonance frequency of the cantilevers was about $1.25 \mathrm{kHz}$. AFM phase contrast was enhanced by treating all the PDMS- $b-\mathrm{P}(\mathrm{DR} 1 \mathrm{MA}-\mathrm{co}-\mathrm{RMA})$ thin films with a $\mathrm{CF}_{4} / \mathrm{O}_{2}$ RIE plasma (plasma conditions are 40 W, $17 \mathrm{sccm} \mathrm{CF} 4$ and $3 \mathrm{sccm} \mathrm{O}$, 45 s) in a PE-100 chamber (Plasma Etch) prior to imaging.

Photoinscription of SRG patterns was performed using a Lloyd's mirror interferometer set up. ${ }^{10,56} \mathrm{~A} p$-polarized laser beam $\left(\lambda_{\mathrm{w}}=532 \mathrm{~nm}\right)$ with a fluence of $30 \mathrm{~mW} \cdot \mathrm{cm}^{-2}$ was split into two beams, one directly incident onto the BCP film and the other reflected by a mirror to which the polymeric layer was perpendicularly attached. The produced sinusoidal patterns have a $357 \mathrm{~nm}$ wave period, independently of the inscribed PDMS- $b$-P(RMA-co-DR1MA) layer.

Small angle X-ray scattering (SAXS) measurements were performed on the CRG-BM02 beamline at the European Synchrotron Radiation Facilities (ESRF) in Grenoble using a photon energy of $10 \mathrm{keV}$. The SAXS patterns were recorded in the classical transmission mode as a function of the scattering vector, $q$, using a XPAD 2D pixel detector $(960 \times 560$ pixels, $130 \mu \mathrm{m}$ pixel size) placed at a distance of $2500 \mathrm{~mm}$ from the sample. The raw data were corrected for scattering due to background noise and the fluctuations of the intensity of the incident beam. Finally, the two-dimensional SAXS patterns were radially averaged in order to obtain the onedimensional scattering profiles.

Grazing incidence small angle X-ray scattering (GISAXS) experiments were performed at the Centre de Recherche Paul Pascal (CRPP) in Bordeaux using a high resolution X-ray spectrometer Xeuss 2.0 from Xenoxs operating at $8.04 \mathrm{keV}$. The incidence angle was set at $0.2^{\circ}$, which is between the critical angle of the BCP film and the silicon substrate. 2D scattering patterns were collected using a PILATUS 300K Dectris detector with an exposure of 30 min. The beam center position and the angular range were calibrated using a silver behenate standard sample. GISAXS 
patterns were reduced using the GIXSGUI package, ${ }^{57}$ where $q_{y}=2 \pi / \lambda\left[\sin \left(2 \theta_{f}\right) \cos \left(\alpha_{f}\right)\right]$ and $q_{z}=2 \pi / \lambda\left[\sin \left(\alpha_{f}\right)+\sin \left(\alpha_{i}\right)\right]$ are the modulus of the scattering vectors in the direction parallel and perpendicular to the substrate plane and $\alpha_{i}, 2 \theta_{f}$ and $\alpha_{f}$ are the incident and scattering angles in the horizontal and vertical directions, respectively.

\section{Synthetic procedures}

Synthesis of mono-carbinol terminated polydimethylsiloxane (P1). The synthesis of the monocarbinol terminated PDMS was performed as in our previous report. ${ }^{41}$ ${ }^{1} \mathrm{H}-\mathrm{NMR}\left(400 \mathrm{MHz}, \mathrm{CDCl}_{3}, \delta\right)$ of $\mathrm{P} 1: 3.6$ (t, 2H, $-\mathrm{CH}_{2}-$ vicinal to $\left.-\mathrm{OH}\right), 1.61\left(\mathrm{~m}, 2 \mathrm{H},-\mathrm{CH}_{2}-\right.$ vicinal to $-\mathrm{CH}_{2}-\mathrm{OH}$ ), 1.54 (br, $2 \mathrm{H},-\mathrm{CH}_{2}-$ of sec-butyl overlaps with $1 \mathrm{H}$ of $-\mathrm{OH}$ groups), 0.93 (m, $6 \mathrm{H},-\mathrm{CH}_{3}$ of sec-butyl), 0.55 (m, $1 \mathrm{H}$, sec-butyl methine overlaps with $2 \mathrm{H}$ of $-\mathrm{Si}-\mathrm{CH}_{2}-$ ), 0.071 (br, $6 \mathrm{H},-\mathrm{CH}_{3}$ of PDMS backbone) all in ppm, as presented in Figure S2.

\section{Synthesis of the macro-CTA mono-4-cyano-4-(phenylcarbonothioylthio) pentanoate} terminated PDMS (P2). 2.6 g (ca. $0.26 \mathrm{mmol}, \mathrm{Mn}_{1 \mathrm{H}-\mathrm{NMR}}=10030 \mathrm{~g} / \mathrm{mol}$ ) of mono-carbinol terminated PDMS and $0.2 \mathrm{~g}(0.68 \mathrm{mmol})$ of DPTS were dissolved in $25 \mathrm{~mL}$ of dry dichloromethane. A solution of $0.35 \quad \mathrm{~g} \quad(1.25 \quad \mathrm{mmol})$ 4-cyano-4(phenylcarbonothioylthio)pentanoic acid in $10 \mathrm{~mL}$ of dry methylene chloride was prepared and added to the PDMS/DPTS solution. Then, $3 \mathrm{~mL}(19.37 \mathrm{mmol})$ of DIPC were dissolved in $10 \mathrm{~mL}$ of dry methylene chloride and added to the reaction mixture at $25^{\circ} \mathrm{C}$. Upon complete addition, the temperature was gradually increased to ca. $45^{\circ} \mathrm{C}$ (solvent reflux). The reagents were left to react for 24 hours under argon and continuous stirring. Upon cooling, the solvent was removed by rotary 
evaporation. The polymer was further purified by four extractions with methanol, yielding after drying $2.5 \mathrm{~g}$ of a pink oil macro-CTA PDMS.

${ }^{1} \mathrm{H}-\mathrm{NMR}$ (400 MHz, $\mathrm{CD}_{2} \mathrm{Cl}_{2}, \delta$ ) of P2: 7.9 (d, 2H, o-ArH), 7.6 (t, 1H, p-ArH), 7.4 (t, 2H, mArH), 4.05 (t, 2H, $-\mathrm{CH}_{2}-$ vicinal to -COO-PDMS chain), 2.6 (m, 2H, vicinal to - $\left(\mathrm{CH}_{3}\right) \mathrm{C}(\mathrm{CN})-$ S-), 2.4 (m, 2H, $-\mathrm{CH}_{2}-$ vicinal to -COO-CTA side), 1.9 (s, 3H, $-\mathrm{CH}_{3}$ of $\left.-\left(\mathrm{CH}_{3}\right) \mathrm{C}(\mathrm{CN})-\mathrm{S}-\right)$, 1.66 (m, 2H, $-\mathrm{CH}_{2}-$ vicinal to $\left.-\mathrm{CH}_{2}-\mathrm{COO}-\mathrm{CTA}\right), 1.55$ (s, 2H, $-\mathrm{CH}_{2}-$ of sec-butyl), 0.93 (m, $6 \mathrm{H}$, $-\mathrm{CH}_{3}$ of sec-butyl), 0.56 (m, 1H, sec-butyl methine overlaps with 2H, $-\mathrm{Si}-\mathrm{CH}_{2}-$ ), 0.08 (br, $6 \mathrm{H},-$ $\mathrm{CH}_{3}$ of PDMS backbone) all in ppm, as presented in Figure S3.

Synthesis of the PDMS-based di-block copolymers (M1 to M4, H4, B4). The synthesized PDMS macro-RAFT agent was used for the homo-polymerization of MMA and DR1MA and also for the DR1MA co-polymerization of with methyl methacrylate, n-butyl methacrylate or n-hexyl methacrylate. Different weight ratio of the DR1 monomer and the alkyl methacrylates were employed, as presented in Table 1. A representative RAFT co-polymerization was as follows, for M4: $0.06 \mathrm{~g}\left(6 \cdot 10^{-3} \mathrm{mmoles}\right)$ of PDMS macro-CTA ( $\mathrm{M}_{\mathrm{n}}$ ca. $\left.10 \mathrm{~kg} / \mathrm{mol}\right), 0.125 \mathrm{~g}(0.327 \mathrm{mmoles})$ of Disperse Red 1 methacrylate, $0.134 \mathrm{~mL}$ (1.253 mmoles) of methyl methacrylate, $0.43 \mathrm{~mL}$ toluene and $18 \mu \mathrm{L}\left(1.09 \cdot 10^{-3} \mathrm{mmoles}\right)$ of AIBN solution in toluene were added in a Schlenk tube. The reaction mixture was deoxygenated by five freeze-vacuum-thaw cycles and then put under an argon atmosphere. The polymerization reaction was carried out at $70^{\circ} \mathrm{C}$ for 96 hours under continuous stirring. Then it was cooled in liquid nitrogen and opened to air. The reaction mixture was diluted with THF. The resulted impure di-block copolymer was purified by precipitation in acetonitrile and then washing with acetonitrile until this non-solvent remains colorless, removing completely the unreacted Disperse Red 1 methacrylate. Then it was precipitated twice in cold 2- 
propanol, removing any residual unfunctionalized PDMS homo-polymer, and dried overnight at $55^{\circ} \mathrm{C}$ under continuous vacuum.

${ }^{1} \mathrm{H}-\mathrm{NMR}\left(400 \mathrm{MHz}, \mathrm{CD}_{2} \mathrm{Cl}_{2}, \delta\right.$ ) for M4: 8.28 (br, $2 \mathrm{H}, \mathrm{o}-\mathrm{ArH}$ to $-\mathrm{NO}_{2}$ ), 7.88 (br, $4 \mathrm{H}, \mathrm{m}-\mathrm{ArH}$ to $\mathrm{NO}_{2}$ and $\mathrm{m}-\mathrm{ArH}$ to $-\mathrm{NEt}_{2}$ ), 6.85 (br, 2H, o- $\mathrm{ArH}$ to $-\mathrm{NEt}_{2}$ ), 4.14 (br, 2H, $-\mathrm{CH}_{2}-$ vicinal to -COOfrom DR1MA), 3.76-3.42 (br, 7H, the two $-\mathrm{CH}_{2}-$ from $-\mathrm{NEt}_{2}$ of DR1MA overlap with 3H of COO- $\mathrm{CH}_{3}$ from MMA), 2.0-1.6 (br, 4H, $-\mathrm{CH}_{2}-$ from the backbone of MMA and DR1MA), 1.30.88 (br, $6 \mathrm{H}, \mathrm{CH}_{3}-$ from the backbone of MMA and DR1MA), 0.79 (br, 3H, $\mathrm{CH}_{3}-$ next to the $\mathrm{CH}_{2}-\mathrm{N}(-\mathrm{azo})-\mathrm{CH}_{2}-$ from DR1MA), 0.11 (br, 6H, $\mathrm{CH}_{3}-$ of PDMS backbone) all in ppm, see

\section{Figure S9.}

${ }^{1} \mathrm{H}-\mathrm{NMR}$ (400 MHz, $\mathrm{CD}_{2} \mathrm{Cl}_{2}, \delta$ ) for B4: 8.27 (br, 2H, o-ArH to - $\mathrm{NO}_{2}$ ), 7.88 (br, 4H, m-ArH to $\mathrm{NO}_{2}$ and $\mathrm{m}-\mathrm{ArH}$ to $-\mathrm{NEt}_{2}$ ), 6.83 (br, 2H, o-ArH to - $\mathrm{NEt}_{2}$ ), 4.12 (br, 2H, $-\mathrm{CH}_{2}-$ vicinal to -COOfrom DR1MA units), 3.92 (br, 2H, $-\mathrm{CH}_{2}-$ vicinal to -COO- from n-BMA units), 3.66 (br, 2H, $\mathrm{CH}_{2}-$ vicinal to $-\mathrm{CH}_{2}-\mathrm{COO}-$ from DR1MA units), 3.51 (br, $2 \mathrm{H},-\mathrm{CH}_{2}-$ vicinal to -N(-azo) $\mathrm{CH}_{2}$ - from DR1MA units), 2.0-1.67 (br, 4H, $-\mathrm{CH}_{2}$ - from the backbone of n-BMA and DR1MA), 1.66-1.08 (br, $4 \mathrm{H},-\mathrm{CH}_{2}-$ vicinal to $-\mathrm{CH}_{2}-\mathrm{COO}-$ and the $-\mathrm{CH}_{2}-$ vicinal to $\mathrm{CH}_{3}-$ from the alkyl chain of n-BMA), 1.07-0.7 (br, 12H, $\mathrm{CH}_{3}-$ from the backbone of n-BMA and DR1MA, $\mathrm{CH}_{3}-$ from the alkyl chain of n-BMA and $\mathrm{CH}_{3}-$ next to the $-\mathrm{CH}_{2}-\mathrm{N}(-\mathrm{azo})-\mathrm{CH}_{2}-$ from DR1MA), 0.11 (br, 6H, $\mathrm{CH}_{3}-$ of PDMS backbone) all in ppm, see Figure S10.

${ }^{1} \mathrm{H}-\mathrm{NMR}\left(400 \mathrm{MHz}, \mathrm{CD}_{2} \mathrm{Cl}_{2}, \delta\right.$ ) for H4: 8.26 (br, $2 \mathrm{H}, \mathrm{o}-\mathrm{ArH}$ to $-\mathrm{NO}_{2}$ ), 7.86 (br, 4H, m-ArH to $\mathrm{NO}_{2}$ and $\mathrm{m}-\mathrm{ArH}$ to $-\mathrm{NEt}_{2}$ ), 6.81 (br, 2H, o- $\mathrm{ArH}$ to $-\mathrm{NEt}_{2}$ ), 4.11 (br, 2H, $-\mathrm{CH}_{2}-$ vicinal to -COOfrom DR1MA units), 3.9 (br, 2H, - $\mathrm{CH}_{2}$ - vicinal to -COO- from n-HMA units), 3.66 (br, 2H, $\mathrm{CH}_{2}-$ vicinal to $-\mathrm{CH}_{2}-\mathrm{COO}-$ from DR1MA units), 3.5 (br, $2 \mathrm{H},-\mathrm{CH}_{2}-$ vicinal to $-\mathrm{N}(-\mathrm{azo})-$ $\mathrm{CH}_{2}$ - from DR1MA units), 2.04-1.67 (br, 4H, $-\mathrm{CH}_{2}$ - from the backbone of n-HMA and DR1MA), 
1.58 (br, $2 \mathrm{H},-\mathrm{CH}_{2}-$ vicinal to $-\mathrm{CH}_{2}-\mathrm{COO}-$ from the alkyl chain of n-HMA), 1.29 (br, $6 \mathrm{H}$, three $-\mathrm{CH}_{2}-$ vicinal to $-\mathrm{CH}_{2}-\mathrm{CH}_{2}-\mathrm{COO}-$ and vicinal to $\mathrm{CH}_{3}-$ from the alkyl chain of n-HMA), 1.070.7 (br, $12 \mathrm{H}, \mathrm{CH}_{3}-$ from the backbone of n-HMA and DR1MA, $\mathrm{CH}_{3}-$ from the alkyl chain of nHMA and $\mathrm{CH}_{3}-$ next to the $-\mathrm{CH}_{2}-\mathrm{N}(-\mathrm{azo})-\mathrm{CH}_{2}-$ from DR1MA), 0.11 (br, $6 \mathrm{H}, \mathrm{CH}_{3}-$ of PDMS backbone) all in ppm, see Figure S11.

\section{Acknowledgements}

The research leading to these results has received partial funding from the PLACYD project (ENIAC Joint Undertaking program) under grant agreement \#621277. The D2AM CRG Beamline is acknowledged for allocating beam time at ESRF for the SAXS experiments. Ahmed Bentaleb is kindly acknowledged for his help with the GISAXS experiments. This work was performed within the framework of the Equipex ELORPrintTec ANR-10-EQPX-28-01 and the LabEx AMADEUS ANR-10-LABEX-0042-AMADEUS with the help of the French state Initiative d'Excellence IdEx ANR-10-IDEX-003-02.

\section{Supporting Information}

${ }^{1} \mathrm{H}-\mathrm{NMR}$ spectra, SEC traces and DSC thermograms of the synthesized materials, 2D GISAXS pattern of solvent-annealed PDMS-b-P(DR1MA-co-RMA)) M4 BCP thin film. 


\section{References.}

(1) Yu, H.; Kobayashi, T. Photoresponsive Block Copolymers Containing Azobenzenes and Other Chromophores. Molecules 2010, 15 (1), 570-603.

https://doi.org/10.3390/molecules15010570.

(2) Zhao, Y.; He, J. Azobenzene-Containing Block Copolymers: The Interplay of Light and Morphology Enables New Functions. Soft Matter 2009, 5 (14), 2686-2693. https://doi.org/10.1039/b821589h.

(3) Yu, H. Photoresponsive Liquid Crystalline Block Copolymers: From Photonics to Nanotechnology. Progress in Polymer Science. Pergamon April 1, 2014, pp 781-815. https://doi.org/10.1016/j.progpolymsci.2013.08.005.

(4) Seki, T. Meso- and Microscopic Motions in Photoresponsive Liquid Crystalline Polymer Films. Macromolecular Rapid Communications. John Wiley \& Sons, Ltd February 1, 2014, pp 271-290. https://doi.org/10.1002/marc.201300763.

(5) Yu, H.; Iyoda, T.; Ikeda, T. Photoinduced Alignment of Nanocylinders by Supramolecular Cooperative Motions. J. Am. Chem. Soc. 2006, 128 (34), 11010-11011. https://doi.org/10.1021/ja064148f.

(6) Morikawa, Y.; Kondo, T.; Nagano, S.; Seki, T. Photoinduced 3D Ordering and Patterning of Microphase-Separated Nanostructure in Polystyrene-Based Block Copolymer. Chem. Mater. 2007, 19 (7), 1540-1542. https://doi.org/10.1021/cm0630845.

(7) Morikawa, Y.; Nagano, S.; Watanabe, K.; Kamata, K.; Iyoda, T.; Seki, T. Optical Alignment and Patterning of Nanoscale Microdomains in a Block Copolymer Thin Film. Adv. Mater. 2006, 18 (7), 883-886. https://doi.org/10.1002/adma.200502573. 
(8) Sano, M.; Nakamura, S.; Hara, M.; Nagano, S.; Shinohara, Y.; Amemiya, Y.; Seki, T.

Pathways toward Photoinduced Alignment Switching in Liquid Crystalline Block

Copolymer Films. Macromolecules 2014, 47 (20), 7178-7186.

https://doi.org/10.1021/ma501803g.

(9) Kim, B. H.; Lee, H. M.; Lee, J.-H.; Son, S.-W.; Jeong, S.-J.; Lee, S.; Lee, D. Il; Kwak, S. U.; Jeong, H.; Shin, H.; et al. Spontaneous Lamellar Alignment in Thickness-Modulated Block Copolymer Films. Adv. Funct. Mater. 2009, 19 (16), 2584-2591.

https://doi.org/10.1002/adfm.200900121.

(10) Aissou, K.; Shaver, J.; Fleury, G.; Pécastaings, G.; Brochon, C.; Navarro, C.; Grauby, S.; Rampnoux, J.-M.; Dilhaire, S.; Hadziioannou, G. Nanoscale Block Copolymer Ordering Induced by Visible Interferometric Micropatterning: A Route towards Large Scale Block Copolymer 2D Crystals. Adv. Mater. 2013, 25 (2), 213-217.

https://doi.org/10.1002/adma.201203254.

(11) Rho, Y.; Aissou, K.; Mumtaz, M.; Kwon, W.; Pécastaings, G.; Mocuta, C.; Stanecu, S.;

Cloutet, E.; Brochon, C.; Fleury, G.; et al. Laterally Ordered Sub-10 Nm Features

Obtained From Directed Self-Assembly of Si-Containing Block Copolymer Thin Films.

Small 2015, 11 (48), 6377-6383. https://doi.org/10.1002/smll.201500439.

(12) Kim, B. H.; Choi, Y.; Kim, J. Y.; Shin, H.; Kim, S.; Son, S. W.; Kim, S. O.; Kim, P. Wrinkle-Directed Self-Assembly of Block Copolymers for Aligning of Nanowire Arrays. Adv. Mater. 2014, 26 (27), 4665-4670. https://doi.org/10.1002/adma.201400804.

(13) Jin, H. M.; Lee, S. H.; Kim, J. Y.; Son, S.-W.; Kim, B. H.; Lee, H. K.; Mun, J. H.; Cha, S. K.; Kim, J. S.; Nealey, P. F.; et al. Laser Writing Block Copolymer Self-Assembly on 
Graphene Light Absorbing Layer. ACS Nano 2016.

https://doi.org/10.1021/acsnano.5b07511.

(14) Jin, H. M.; Park, D. Y.; Jeong, S.-J. J.; Lee, G. Y.; Kim, J. Y. S. Y.; Mun, J. H.; Cha, S. K.; Lim, J.; Kim, J. Y. S. Y.; Kim, K. H.; et al. Flash Light Millisecond Self-Assembly of High $\chi$ Block Copolymers for Wafer-Scale Sub-10 Nm Nanopatterning. Adv. Mater. 2017, 29 (32), 1700595. https://doi.org/10.1002/adma.201700595.

(15) Park, S.; Lee, D. H.; Xu, J.; Kim, B.; Hong, S. W.; Jeong, U.; Xu, T.; Russell, T. P. Macroscopic 10-Terabit-per-Square-Inch Arrays from Block Copolymers with Lateral Order. Science 2009, 323 (5917), 1030-1033. https://doi.org/10.1126/science.1168108.

(16) Hong, S. W.; Huh, J.; Gu, X.; Lee, D. H.; Jo, W. H.; Park, S.; Xu, T.; Russell, T. P. Unidirectionally Aligned Line Patterns Driven by Entropic Effects on Faceted Surfaces. Proc. Natl. Acad. Sci. U. S. A. 2012, 109 (5), 1402-1406. https://doi.org/10.1073/pnas.1115803109.

(17) Zhu, Y.; Aissou, K.; Andelman, D.; Man, X. Orienting Cylinder-Forming Block Copolymer Thin Films: The Combined Effect of Substrate Corrugation and Its Surface Energy. Macromolecules 2019, 52 (3), 1241-1248. https://doi.org/10.1021/acs.macromol.8b02302.

(18) Matsuo, Y.; Konno, R.; Ishizone, T.; Goseki, R.; Hirao, A. Precise Synthesis of Block Polymers Composed of Three or More Blocks by Specially Designed Linking Methodologies in Conjunction with Living Anionic Polymerization System; Multidisciplinary Digital Publishing Institute, 2013; Vol. 5, pp 1012-1040. https://doi.org/10.3390/polym5031012. 
(19) Pitet, L. M.; Wuister, S. F.; Peeters, E.; Kramer, E. J.; Hawker, C. J.; Meijer, E. W. WellOrganized Dense Arrays of Nanodomains in Thin Films of Poly(Dimethylsiloxane)- b Poly(Lactide) Diblock Copolymers. Macromolecules 2013, 46 (20), 8289-8295. https://doi.org/10.1021/ma401719p.

(20) Wei, R.; He, Y.; Wang, X. Diblock Copolymers Composed of a Liquid Crystalline Azo Block and a Poly(Dimethylsiloxane) Block: Synthesis, Morphology and Photoresponsive Properties. RSC Adv. 2014, 4 (102), 58386-58396. https://doi.org/10.1039/c4ra09863c.

(21) Lim, K. T.; Webber, S. E.; Johnston, K. P. Synthesis and Characterization of Poly(Dimethyl Siloxane)-Poly[Alkyl (Meth)Acrylic Acid] Block Copolymers. Macromolecules 1999, 32 (9), 2811-2815. https://doi.org/10.1021/ma981658o.

(22) Morgan, A. M.; Pollack, S. K.; Beshah, K. Synthesis and Multidimensional NMR Characterization of PDMS-b-PS Prepared by Combined Anionic Ring-Opening and Nitroxide-Mediated Radical Polymerization. Macromolecules 2002, 35 (11), 4238-4246. https://doi.org/10.1021/ma0114178.

(23) Qin, X.; Li, Y.; Zhou, F.; Ren, L.; Zhao, Y.; Yuan, X. PolydimethylsiloxanePolymethacrylate Block Copolymers Tethering Quaternary Ammonium Salt Groups for Antimicrobial Coating. Appl. Surf. Sci. 2015, 328, 183-192. https://doi.org/10.1016/j.apsusc.2014.12.019.

(24) Scarpaci, A.; Cabanetos, C.; Blart, E.; Montembault, V.; Fontaine, L.; Rodriguez, V.; Odobel, F. Postfunctionalization of Poly(Propargyl Methacrylate) Using Copper Catalyzed 1,3-Dipolar Huisgen Cycloaddition: An Easy Route to Electro-Optic Materials. J. Polym. Sci. Part A Polym. Chem. 2009, 47 (21), 5652-5660. 
https://doi.org/10.1002/pola.23606.

(25) Faccini, M.; Balakrishnan, M.; Torosantucci, R.; Driessen, A.; Reinhoudt, D. N.;

Verboom, W. Facile Attachment of Nonlinear Optical Chromophores to Polycarbonates. Macromolecules 2008, 41 (22), 8320-8323. https://doi.org/10.1021/ma801875w.

(26) Bag, D. S.; Alam, S. Synthesis and Characterization of Photoactive Chiral Copolymers of (S)-N-(1-Phenyl Ethyl) Methacrylamide and Disperse Red 1 Methacrylate. J. Appl. Polym. Sci. 2012, 125 (4), 2595-2603. https://doi.org/10.1002/app.36369.

(27) Ding, L.; Russell, T. P. A Photoactive Polymer with Azobenzene Chromophore in the Side Chains. Macromolecules 2007, 40 (6), 2267-2270. https://doi.org/10.1021/ma062653r.

(28) Jie, X. U.; Wei, Z.; Nianchen, Z.; Jian, Z.; Zhenping, C.; Yan, X. U.; Xiulin, Z. Synthesis of Azobenzene-Containing Polymers via RAFT Polymerization and Investigation on Intense Fluorescence from Aggregates of Azobenzene-Containing Amphiphilic Diblock Copolymers. J. Polym. Sci. Part A Polym. Chem. 2008, 46 (16), 5652-5662. https://doi.org/10.1002/pola.22886.

(29) Zhao, Y.; Qi, B.; Tong, X.; Zhao, Y. Synthesis of Double Side-Chain Liquid Crystalline Block Copolymers Using RAFT Polymerization and the Orientational Cooperative Effect. Macromolecules 2008, 41 (11), 3823-3831. https://doi.org/10.1021/ma8000302.

(30) Zenati, A.; Han, Y. K. Synthesis and Properties of Azo-Based ABC Triblock Copolymers Owning Interaction and Composition Parameters That Influence Their Phase Behaviors. Macromolecules 2018, 51 (1), 101-114. https://doi.org/10.1021/acs.macromol.7b02012. 
(31) Pietsch, C.; Hoogenboom, R.; Schubert, U. S. Soluble Polymeric Dual Sensor for Temperature and PH Value. Angew. Chemie - Int. Ed. 2009, 48 (31), 5653-5656. https://doi.org/10.1002/anie.200901071.

(32) Kravchenko, A.; Shevchenko, A.; Ovchinnikov, V.; Priimagi, A.; Kaivola, M. Optical Interference Lithography Using Azobenzene-Functionalized Polymers for Micro-and Nanopatterning of Silicon. Adv. Mater. 2011, 23 (36), 4174-4177. https://doi.org/10.1002/adma.201101888.

(33) Goulet-Hanssens, A.; Corkery, T. C.; Priimagi, A.; Barrett, C. J. Effect of Head Group Size on the Photoswitching Applications of Azobenzene Disperse Red 1 Analogues. $J$. Mater. Chem. C 2014, 2 (36), 7505-7512. https://doi.org/10.1039/c4tc00996g.

(34) Cao, H. Z.; Zhang, W.; Zhu, J.; Chen, X. R.; Cheng, Z. P.; Wu, J. H.; Zhu, X. L. Azo Polymers with Electronical Push and Pull Structures Prepared via RAFT Polymerization and Its Photoinduced Birefringence Behavior. Express Polym. Lett. 2008, 2 (8), 589-601. https://doi.org/10.3144/expresspolymlett.2008.71.

(35) Pietsch, C.; Hoogenboom, R.; Schubert, U. S. PMMA Based Soluble Polymeric Temperature Sensors Based on UCST Transition and Solvatochromic Dyes. Polym. Chem. 2010, 1 (7), 1005-1008. https://doi.org/10.1039/c0py00162g.

(36) Son, J. G.; Gotrik, K. W.; Ross, C. A. High-Aspect-Ratio Perpendicular Orientation of PSb -PDMS Thin Films under Solvent Annealing. ACS Macro Lett. 2012, 1 (11), 12791284. https://doi.org/10.1021/mz300475g.

(37) Bai, W.; Gadelrab, K.; Alexander-Katz, A.; Ross, C. A. Perpendicular Block Copolymer Microdomains in High Aspect Ratio Templates. Nano Lett. 2015, 15 (10), 6901-6908. 
https://doi.org/10.1021/acs.nanolett.5b02815.

(38) Girardot, C.; Böhme, S.; Archambault, S.; Salaün, M.; Latu-Romain, E.; Cunge, G.; Joubert, O.; Zelsmann, M. Pulsed Transfer Etching of PS-PDMS Block Copolymers SelfAssembled in 193 Nm Lithography Stacks. ACS Appl. Mater. Interfaces 2014, 6 (18), 16276-16282. https://doi.org/10.1021/am504475q.

(39) Zhu, Y.; Zhou, Y.; Chen, Z.; Lin, R.; Wang, X. Photoresponsive Diblock Copolymers Bearing Strong Push-Pull Azo Chromophores and Cholesteryl Groups. Polymer (Guildf). 2012, 53 (16), 3566-3576. https://doi.org/10.1016/j.polymer.2012.05.063.

(40) Yang, C. A.; Chen, L.; Huang, H.; Lu, Y.; Xiong, B.; Liu, Y.; Yi, J. Effects of Molecular Weight on Dual Light- and Thermo-Responsive Behaviors of Homopolymers with Azobenzene Units and Terminal Oligo(Ethylene Glycol) Units. Polym. Int. 2017, 66 (12), 1819-1826. https://doi.org/10.1002/pi.5434.

(41) Spiridon, M. C.; Aissou, K.; Mumtaz, M.; Brochon, C.; Cloutet, E.; Fleury, G.; Hadziioannou, G. Surface Relief Gratings Formed by Microphase-Separated Disperse Red 1 Acrylate-Containing Diblock Copolymers. Polymer (Guildf). 2018, 137, 378-384. https://doi.org/10.1016/j.polymer.2018.01.032.

(42) Natansohn, A.; Rochon, P.; Gosselin, J.; Xie, S. Azo Polymers for Reversible Optical Storage. 1. Poly[4'-[[2-(Acryloyloxy)Ethyl]Ethylamino]-4-Nitroazobenzene]. Macromolecules 1992, 25 (8), 2268-2273. https://doi.org/10.1021/ma00034a031.

(43) Xie, S.; Natansohn, A.; Rochon, P. Microstructure of Copolymers Containing Disperse Red 1 and Methyl Methacrylate. Macromolecules 1994, 27 (7), 1885-1890. https://doi.org/10.1021/ma00085a034. 
(44) Sinturel, C.; Vayer, M.; Morris, M.; Hillmyer, M. A. Solvent Vapor Annealing of Block Polymer Thin Films. Macromolecules 2013, 46 (14), 5399-5415.

https://doi.org/10.1021/ma400735a.

(45) Stein, G. E.; Kramer, E. J.; Li, X.; Wang, J. Layering Transitions in Thin Films of Spherical-Domain Block Copolymers. Macromolecules 2007, 40 (7), 2453-2460. https://doi.org/10.1021/ma0625509.

(46) Aissou, K.; Fleury, G.; Pecastaings, G.; Alnasser, T.; Mornet, S.; Goglio, G.; Hadziioannou, G. Hexagonal-to-Cubic Phase Transformation in Composite Thin Films Induced by FePt Nanoparticles Located at PS/PEO Interfaces. Langmuir 2011, 27 (23), 14481-14488. https://doi.org/10.1021/la2036983.

(47) Barton, A. M. Handbook of Polymer-Liquid Interaction Parameters and Solubility Parameters; Routledge, 2018. https://doi.org/10.1201/9780203752616.

(48) Lee, B.; Park, I.; Yoon, J.; Park, S.; Kim, J.; Kim, K.-W.; Chang, T.; Ree, M. Structural Analysis of Block Copolymer Thin Films with Grazing Incidence Small-Angle X-Ray Scattering. Macromolecules 2005, 38 (10), 4311-4323. https://doi.org/10.1021/ma047562d.

(49) Busch, P.; Rauscher, M.; Moulin, J. F.; Müller-Buschbaum, P. Debye-Scherrer Rings from Block Copolymer Films with Powder-like Order. J. Appl. Crystallogr. 2011, 44 (2), 370379. https://doi.org/10.1107/S0021889810053823.

(50) Saito, I.; Miyazaki, T.; Yamamoto, K. Depth-Resolved Structure Analysis of Cylindrical Microdomain in Block Copolymer Thin Film by Grazing-Incidence Small-Angle X-Ray Scattering Utilizing Low-Energy X-Rays. Macromolecules 2015, 48 (22), 8190-8196. 
https://doi.org/10.1021/acs.macromol.5b01883.

(51) Fukuda, T.; Matsuda, H.; Shiraga, T.; Kimura, T.; Kato, M.; Viswanathan, N. K.; Kumar, J.; Tripathy, S. K. Photofabrication of Surface Relief Grating on Films of Azobenzene Polymer with Different Dye Functionalization. Macromolecules 2000, 33 (11), 42204225. https://doi.org/10.1021/ma991803d.

(52) Qiang, Z.; Wadley, M. L.; Vogt, B. D.; Cavicchi, K. A. Facile Non-Lithographic Route to Highly Aligned Silica Nanopatterns Using Unidirectionally Aligned Polystyrene-BlockPolydimethylsiloxane Films. J. Polym. Sci. Part B Polym. Phys. 2015, 53 (15), 10581064. https://doi.org/10.1002/polb.23740.

(53) Cummins, C.; Ghoshal, T.; Holmes, J. D.; Morris, M. A. Strategies for Inorganic Incorporation Using Neat Block Copolymer Thin Films for Etch Mask Function and Nanotechnological Application. Adv. Mater. 2016, 28 (27), 5586-5618. https://doi.org/10.1002/adma.201503432.

(54) Legrain, A.; Fleury, G.; Mumtaz, M.; Navarro, C.; Arias-Zapata, J.; Chevalier, X.; Cayrefourcq, I.; Zelsmann, M. Straightforward Integration Flow of a Silicon-Containing Block Copolymer for Line-Space Patterning. ACS Appl. Mater. Interfaces 2017, 9 (49), 43043-43050. https://doi.org/10.1021/acsami.7b12217.

(55) Gotrik, K. W.; Hannon, A. F.; Son, J. G.; Keller, B.; Alexander-Katz, A.; Ross, C. A. Morphology Control in Block Copolymer Films Using Mixed Solvent Vapors. ACS Nano 2012, 6 (9), 8052-8059. https://doi.org/10.1021/nn302641z.

(56) Ubukata, T.; Isoshima, T.; Hara, M. Wavelength-Programmable Organic DistributedFeedback Laser Based on a Photoassisted Polymer-Migration System. Adv. Mater. 2005, 
17 (13), 1630-1633. https://doi.org/10.1002/adma.200402080.

(57) Jiang, Z. GIXSGUI : A MATLAB Toolbox for Grazing-Incidence X-Ray Scattering Data Visualization and Reduction, and Indexing of Buried Three-Dimensional Periodic Nanostructured Films. J. Appl. Crystallogr. 2015, 48 (3), 917-926. https://doi.org/10.1107/s1600576715004434. 
Use for table of content only

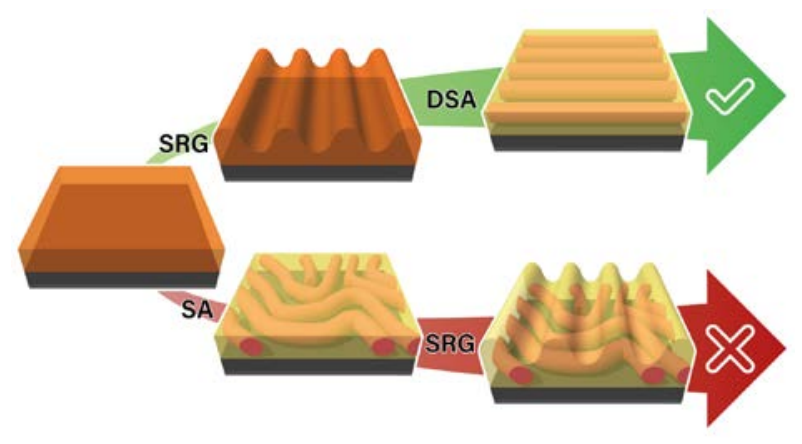

